\title{
IMPLICAÇÕES DA ECONOMIA SOLIDÁRIA PARA O DESENVOLVIMENTO SOCIAL
}

Implications of the solidary economy for social development

Implicaciones de la economía solidaria para el desarrollo social

\section{Jayrton Noleto de Macedo*1, Pietra Sally Biazussi Montanuci², Gecilane} Ferreira ${ }^{3}$,

${ }^{1}$ Mestrando em Demandas Populares e Dinâmicas Populares (UFT), Graduação em Direito (UNITPAC), Bolsista CAPES, Araguaína-TO, Brasil.

2 Acadêmica de Ciências Biológicas, Universidade Federal do Tocantins (UFT), Porto Nacional - TO, Brasil.

${ }^{3}$ Biólogo, Doutor em Educação em Ciências e Matemática (UFMT), Docente da UFT, Araguaína-TO, Brasil

*Correspondência: NEPEBIO. Avenida Paraguai (esquina com a Rua Uxiramas), s/n Setor - Bairro da Cimba, Araguaína - TO, CEP: 77824-838.e-mail: jayrtonnoleto@outlook.com..

\section{RESUMO}

A economia solidária (ES) possui o intuito de gerar o incremento de valores equitativos e redes de comércios, tendendo buscar os benefícios do desenvolvimento produtivo, de forma que tudo seja dividido entre os participantes dessa prática. A ES é uma ação que visa promover a acessibilidade social às pequenas comunidades e com isso, implica em promover o desenvolvimento na perspectiva do teórico Amartya Sen (2000). Objetiva o presente artigo analisar de que forma a economia solidária toca o desenvolvimento. Metodologicamente, fez-se um levantamento bibliográfico por meio do método dedutivo. A ES possui forte influência no desenvolvimento social porque suas características consistem em valorizar socialmente os indivíduos trabalhadores, satisfazendo as necessidades de todos; incentivar a criatividade tecnológica; reconhecer o lugar fundamental da mulher e do feminino numa economia fundada na solidariedade; buscar a relação de intercâmbio respeitoso com a natureza; promover os valores da cooperação e da solidariedade. Foi possível perceber que a ES se mostra como uma boa alternativa para promover o desenvolvimento social e econômico em pequenas comunidades. A prática proporciona benefícios diversos a população, meio ambiente e economia local. Consequentemente, busca sanar as vulnerabilidades de grupos sociais, muitas vezes esquecidos e desvalorizados.

Palavras-chave: Desenvolvimento, Liberdades, Vulnerabilidade.

\section{ABSTRACT}

The solidarity economy (ES) has the intention of generating an increase in equitable values and trade networks, tending to seek the benefits of productive development, so that everything is divided among the participants in this practice. Higher education is an action that aims to promote social accessibility to small communities and with that, it implies promoting development from the perspective of theorist Amartya Sen (2000). The purpose of this article is to analyze how the solidarity economy touches development. Methodologically, a bibliographic survey was made through the deductive method. Higher education has a strong influence on social development because its characteristics consist of socially valuing working individuals, satisfying everyone's needs; encourage technological creativity; recognize the fundamental place of women and women in an economy founded on solidarity; seek the relationship of respectful exchange with nature; promote the values of cooperation and solidarity. It was possible to perceive that HE is a good alternative to promote social and economic development in small communities. The practice provides diverse benefits to the population, the environment and the local economy. Consequently, it seeks to remedy the vulnerabilities of social groups, which are often overlooked and devalued.

Keywords: Development, Freedoms, Vulnerability. 


\section{RESUMEN}

La economía solidaria (ES) tiene la intención de generar un aumento en los valores equitativos y las redes comerciales, tendiendo a buscar los beneficios del desarrollo productivo, para que todo se divida entre los participantes en esta práctica. La educación superior es una acción que tiene como objetivo promover la accesibilidad social a las comunidades pequeñas y con eso, implica promover el desarrollo desde la perspectiva del teórico Amartya Sen (2000). El propósito de este artículo es analizar cómo la economía solidaria toca el desarrollo. Metodológicamente, se realizó una encuesta bibliográfica a través del método deductivo. La educación superior tiene una fuerte influencia en el desarrollo social porque sus características consisten en valorar socialmente a las personas que trabajan y satisfacer las necesidades de todos; alentar la creatividad tecnológica; reconocer el lugar fundamental de la mujer y la mujer en una economía fundada en la solidaridad; buscar la relación de intercambio respetuoso con la naturaleza; Promover los valores de cooperación y solidaridad. Era posible percibir que ES es una buena alternativa para promover el desarrollo social y económico en pequeñas comunidades. La práctica proporciona diversos beneficios a la población, el medio ambiente y la economía local. En consecuencia, busca remediar las vulnerabilidades de los grupos sociales, que a menudo se pasan por alto y se devalúan.

Descriptores: Desarrollo, Libertades, Vulnerabilidad.

\section{INTRODUÇÃO}

Essa pesquisa se propõe a estudar os conceitos da Economia Solidária (ES), como ela é na prática, suas perspectivas, e de que forma ela toca o desenvolvimento social. $\mathrm{O}$ ideal adotado de desenvolvimento social é o elencado pela teoria de liberdades substantivas do autor Amartya Sen (2000).

A ES pode ser a solução equilibrada para as necessidades criadas aos menos favorecidos pelo sistema de produção capitalista. As comunidades que se veem afastadas dos grandes centros urbanos, seja por falta de oportunidades, seja por incapacidade desse sistema capitalista de fornecer trabalho e cidadania para o coletivo, tem como alternativa, a ES. Tal alternativa é responsável não só por gerar atividade laboral as pessoas em situação de desalento, mas, por fornecer ao indivíduo, a capacidade de desenvolvimento.

O desenvolvimento citado anteriormente tem seu conceito na teoria de Amartya Sen (2000) e será o que utilizaremos ao longo do trabalho. Amartya Sen (2000) aduz que, o desenvolvimento significa promover um ambiente coletivo no qual não haja obstáculo a uma pessoa, sendo assim, esse indivíduo poderia fazer da vida o que bem entendesse sem sofrer influência de fatores como: segurança precária, saúde pública inexistente, ausência de recursos financeiros, falta de liberdades e capacidade política e civil.

Assim, a ES é importante para a perspectiva de desenvolvimento social porque ela é capaz de gerar para as pessoas em desalento, uma oportunidade de trabalho digno, de maneira que os participantes da ES possam retomar seus lugares enquanto indivíduos sociais. Por exemplo, a pessoa que faz parte de um ES, tem a capacidade de compra retomada, faz uma atividade laboral coletiva, interage com outras pessoas, consegue manter suas necessidades pessoais e financeiras, além de boa alimentação e segurança alimentar.

\section{MATERIAIS E MÉTODOS}

A presente pesquisa tem como características metodológicas a utilização do método dedutivo. Também se utilizou da base teórica de Amartya Sen (2000), de forma a mobilizar a sua teoria com objetivo de analisar o objeto da pesquisa. Trata-se de um estudo descritivo através do procedimento técnico de pesquisa bibliográfica e documental. 


\section{RESULTADOS E DISCUSSÃO}

\section{Economia solidária: conceitos e características}

A ES é uma prática pela qual vários agricultores trabalham em conjunto, objetivando alguns princípios, dentre os quais podem-se destacar: valorização social do trabalho humano; a satisfação plena das necessidades do coletivo; criatividade tecnológica da atividade econômica; reconhecimento da mulher na atividade de produção; sustentabilidade, cooperação e solidariedade (CEA, 2003).

Para entender melhor do que se trata uma ES é importante saber que ela é um conjunto de agentes econômicos ${ }^{1}$ que buscam contribuir para o progresso próprio e coletivo dos envolvidos, valorizando as vantagens da cooperação. Além disso, a ES promove o desenvolvimento de redes de comércio a preços justos, com alimentos saudáveis. Procura-se nessa prática coletiva, benefícios do desenvolvimento produtivo de forma que eles possam ser repartidos equitativamente entre grupos que participem dessa parceria (CEA, 2003). Veja um conceito: “A economia solidária relaciona: produção - distribuição consumo. Esta é uma perspectiva econômica, que está submetida e relacionada às construções sociais, culturais, políticas" (SCHULTZ, 2017, p.17).

As relações de poder mencionada na citação dizem respeito a condição de empoderamento pelo qual o coletivo que participa da ES pode instituir para si. Relação capaz de gerar desenvolvimento social, que é divergente daquele conceito inicialmente pensando, à medida que a ES gera "a prática de outro tipo de desenvolvimento, comprometido com o ser humano e com o planeta, é vivenciada por muitos trabalhadores e trabalhadoras do campo e da cidade." (CEA, 2016, p. 5).
A ES, apesar de parecer um pouco difícil de se pôr em prática, por conta de alguns conceitos que vão de encontro ao capitalismo devastador, pode ser encontrada em várias atividades laborais que prioriza: colaboração, autossuficiência e humanização na atividade econômica. A título de exemplo, temos:

Agricultura familiar e camponesa, hortas urbanas, cooperativas de diferentes tipos de trabalho autogestionário, empreendimentos econômicos solidários, centrais de comercialização, associações, entidades de assessoria, rede de gestores, bancos comunitários, grupos de trocas solidárias, grupos de consumo e fundos rotativos solidários. (CEA, 2016, p. 5-6).

Dessa forma, pode-se observar a quantidade de atividades que são desenvolvidas dentro dos preceitos da ES. De acordo com a Secretaria Nacional de Economia Solidária (BRASIL, 2013, p.5), "na região norte foram inseridos no Sistema Nacional de Informações em Economia Solidária (SIES) 3.128 ES, com destaque para o Estado do Pará com 1.359 ES, o que corresponde a $43 \%$ do total de ES da região". Observe a tabela 1 abaixo:

Tabela 1. ES por unidade da Federação- Região Norte

\begin{tabular}{l|l|l}
\hline UF & Freq. & $\%$ \\
\hline Acre & 341,0 & 10,9 \\
\hline Amapá & 328,0 & 10,5 \\
\hline Amazonas & 378,0 & 12,1 \\
\hline Pará & $1,359,0$ & 43,4 \\
\hline Rondônia & 238,0 & 7,6 \\
\hline Roraima & 80,0 & 2,6 \\
\hline Tocantins & 404,0 & 12,9 \\
\hline Total & $3.128,0$ & 100 \\
\hline
\end{tabular}

Fonte: SIES/Base Atualizada 2013. Adaptado pelo autor

O estado do Pará é o que mais tem ES dentre todos os demais apresentados na tabela 1. Isso pode ser consequência da marginalização desse estado frente as

\footnotetext{
1 Podem ser produtores rurais locais, ONG's, instituições comunitárias, redes de cooperativas, grupos de consumidores.
} 
atividades industriais e capitalistas. Sabe-se que o estado em questão é de difícil acesso logístico para as indústrias, por questões ambientais e político/ econômicas. No entanto, por ser região amazônica, concentra grande parte de atividades voltadas a agricultura de subsistência, o que pode facilitar a criação das ES.

Assim, é perceptível que a prática de ES contribui para o desenvolvimento social daqueles que estão inseridos no seu processo. Tais inferência se dão pela análise de como funciona uma ES, seus objetivos e princípios.

\section{CONCLUSÃO}

Percebe-se assim que, os princípios, objetivos e metodologia da ES são totalmente voltados para a valorização do humano e do social. As ES's, para necessariamente existirem precisam cumprir etapas que valorizem o coletivo e o social. El se mostra como uma boa alternativa para promover o desenvolvimento social e econômico em pequenas comunidades afastadas dos espaços urbanos. A prática proporciona benefícios diversos a população, meio ambiente e economia local.

\section{AGRADECIMENTO}

O presente trabalho foi realizado com apoio da Coordenação de Aperfeiçoamento de Pessoal de Nível
Superior - Brasil (CAPES) - Código de

Financiamento 001

Todos os autores declararam não haver qualquer potencial conflito de interesses referente a este artigo.

\section{REFERÊNCIAS}

BRASIL. Secretaria Nacional de Economia Solidária. Divulgação dos dados prelimiraes do SIES 2013. Brasília: 2013. Disponível em: http://sies.ecosol.org.br/images/resultado/sies divulgacao-de-dados-preliminares-2013.pdf. Acesso em: 10 ago de 2019.

CENTRO DE ESTUDOS DE ASSESSORIA (CEA). Fórum Brasileiro de Economia Solidária (FBES). Carta de princípios da Economia Solidária. 2003. III Plenária Nacional da Economia Solidária. Disponível em: https://fbes.org.br/2005/05/02/cartade-principios-da-economia-solidaria/. Acesso em: 19 jun. 2019.

CENTRO DE ESTUDOS DE ASSESSORIA (CEA). Boas práticas em economia solidária no Brasil/Texto de Claudia Lima - Brasília: CEA; FBES, $2016 . \quad$ Disponível em: file:///C:/Users/jayrt/Desktop/Cartilha-BOAS-

PRATICAS-CEA-29-06.pdf. Acesso em: 10 ago de 2019.

SEN, Amartya. Desenvolvimento como liberdade. São Paulo: Companhia das Letras, 2000.

SCHUTZ, Fernanda. Território e poder local. Economia Solidária - Alguns Conceitos Básicos. Porto Alegre. 2017. Disponível em: http://camp.org.br/files/2017/11/Cartilha-EcoSolConceitos-Basicos-CFES-Sul.pdf. Acesso em: 10 ago de 2019. 